\title{
Successful use of recombinant activated factor VII administered via automated bolus pump following emergency laparoscopic appendectomy in a patient with mild congenital FVII deficiency: Case report
}

\author{
Robert Klaassen ${ }^{1}$ and Heather Perkins ${ }^{1}$ \\ ${ }^{1}$ Children's Hospital of Eastern Ontario
}

November 25, 2020

\begin{abstract}
Surgery in patients with factor VII (FVII) deficiency may be complicated by severe bleeding, requiring regular bolus doses of replacement therapy. Eptacog alfa (activated) is a recombinant activated FVII (rFVIIa) used for the treatment of bleeds and perioperative management in patients with approved bleeding disorders, including FVII deficiency. We report that using the B-Braun Perfusor \& Space syringe pump to automatically deliver regular bolus rFVIIa doses provided effective hemostasis and no safety concerns in a patient with mild FVII deficiency undergoing emergency laparoscopic appendectomy. Additional benefits included saving nursing/hospital resources, reducing treatment burden and reassurance for the patient/family, and healthcare providers.
\end{abstract}

\section{Hosted file}

FVII Deficiency case_(Perkins_Klaassen)_FINAL_23Nov2020_v2.0.pdf available at https: //authorea.com/users/378559/articles/495023-successful-use-of-recombinant-activatedfactor-vii-administered-via-automated-bolus-pump-following-emergency-laparoscopicappendectomy-in-a-patient-with-mild-congenital-fvii-deficiency-case-report 